\title{
Remote Monitoring Improves Diabetes Control in Urban Indian Population within 3 Months
}

\author{
Thara Murali* \\ Department of Diet and Nutrition, Diabetacare, Bangalore, India
}

*Corresponding author: Thara Murali, Chief Dietician/General Manager Clinical Services, Department Of Diet n Nutrition, Diabetacare, Bangalore

Submission: : March 14, 2018; Published: 眥 April 19, 2018

\section{Introduction}

The aim of this study was to compare change in HbA1c and anthropometric measurement in subjects who have accepted remote monitoring for their diabetes management

\section{Subject and methods}

a. Diabetes subjects who accepted remote monitoring

b. Patients completing 3 months follow up and had paired data

c. Comparison were made between initial HbA1c and that after 3 months using paired t test

d. BMI and waist circumference

\section{Results}

a. $\quad$ Total no of patients $=56$

b. Mean age $53.4+/-12.7$ years

c. Male: Female $=28: 28$

d. All had paired observation 3 months apart

e. Significant reduction in $\mathrm{HbA1c}$ from $9.5 \%$ to $8.4 \%$ [Figure 1]

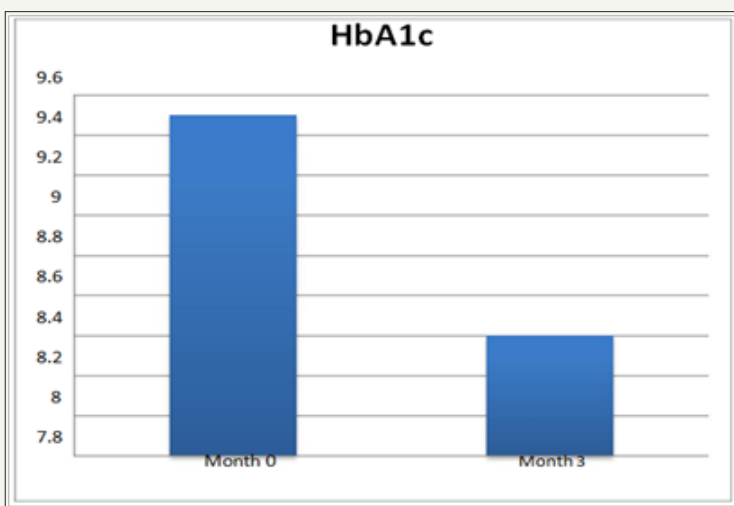

Figure 1: Reduction in $\mathrm{HbA1c}$ from $9.5 \%$ to $8.4 \%$. f. Statistically non-significant reduction in Waist circumference \& BMI [Figure 2 \& 3]

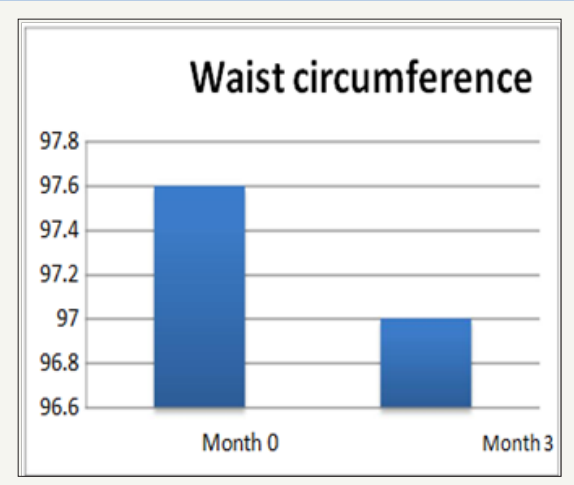

Figures 2: Statistically non-significant reduction in waist circumference.

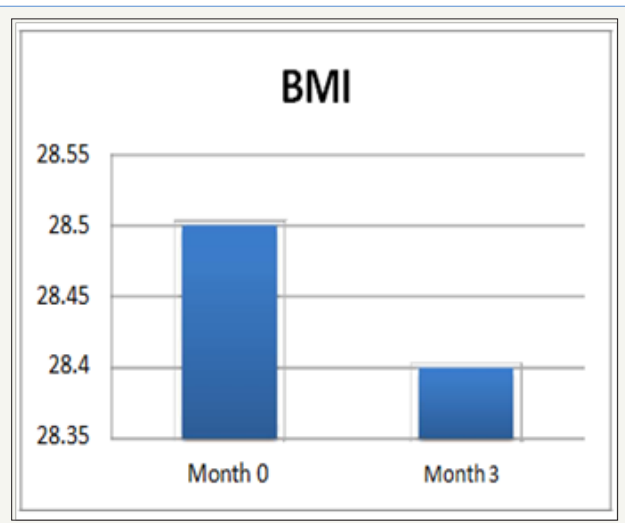

Figures 3: Statistically non-significant reduction in BMI.

\section{Discussion}

Remote monitoring can be successfully used to improve diabetes control in patients with diabetes.

There was no effect on BMI or waist circumference possibly due to short duration 
Long term data will be needed which we are collecting now

\section{Conclusion}

Advantages of remote monitoring for

Patients: Do not have to come to clinic, have friendly advice 24/7,

Doctors: Not disturbed during their busy hours at work or home, have access to all data at smart phone via App [Tables 1-3],

Total no of patients $=56$

Mean age $53.4+/-12.7$ years

Male: Female $=28: 28$

All had paired observation 3 months apart

Table 1

\begin{tabular}{|c|c|c|c|}
\hline & BMI_1 & BMI_2 & P value \\
\hline MEAN & 28.5 & 28.4 & 0.73 \\
\hline SD & 5.2 & 4.7 & \\
\hline
\end{tabular}

Table 2

\begin{tabular}{|c|c|c|c|}
\hline & $\begin{array}{c}\text { Waist } \\
\text { Circum_1 }\end{array}$ & $\begin{array}{c}\text { Waist } \\
\text { Circum_2 }\end{array}$ & P Value \\
\hline MEAN & 97.6 & 97 & 0.87 \\
\hline SD & 14.7 & 10.8 & \\
\hline
\end{tabular}

Table 3

\begin{tabular}{|c|c|c|c|}
\hline & Hba1c_1 & Hba1c_2 & P value \\
\hline MEAN & 9.5 & 8.4 & 0.0002 \\
\hline SD & 2.2 & 1.8 & \\
\hline
\end{tabular}

Modern technology can be a useful tool for providing effective management of diabetes when used with appropriate clinical support. However, its use in Indian setting has not been established.
We have introduced telemedicine in our clinic in Bangalore, where patient's blood sugar, blood pressure and dietary intake can be monitored and appropriate advice can be given by clinicians by telephone. We wanted to study if such intervention can demonstrate objective difference.

\section{Aim}

The aim of this study was to compare change in HbA1c and anthropometric measurement in subjects who have accepted remote monitoring for their diabetes management.

\section{Subjects \& methods}

Diabetes subjects who accepted remote monitoring were studied. Only those subjects who had completed 3 months follow up and had paired data were studied. Comparisons were made between initial $\mathrm{HbA1c}$ and that after 3 months using paired t test. Similar comparisons were also made in BMI and waist circumference. There were not enough data to compare lipid profiles so it was not analysed.

\section{Results}

56 subjects ( 28 males) with mean age of $53.4(+/-12.7)$ years had accepted remote monitoring and completed 3 months of follow up check up. There was a significant reduction in HbA1c at 3 months follow up $(9.5+/-2.2 \%$ vs $8.4+/-1.8 \%$; $p=0.0002)$ with remote monitoring. 41 subjects had reduction in HbA1c, however 15 in subjects it increased within 3 months. There was no difference in BMI or waist circumference during this time.

\section{Discussion}

Our results show that remote monitoring can be successfully used to improve diabetes control in subjects with diabetes. There was no effect on BMI or waist circumference as the duration might have been short. Long term data will be needed to demonstrate its efficacy in improving overall diabetes management.
Creative Commons Attribution 4.0 International License

For possible submissions Click Here

\section{Submit Article}

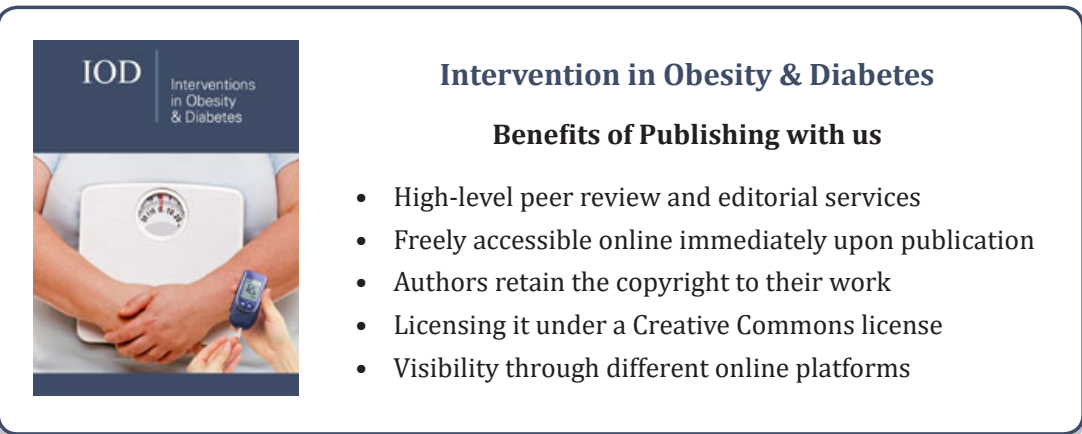

